\title{
GAMBARAN KLINIS GINGIVA PADA IBU HAMIL DI PUSKESMAS BAHU KECAMATAN MALALAYANG
}

\author{
${ }^{1}$ Lucyana S. Angwirawan \\ ${ }^{2}$ Shane H. R. Ticoalu \\ ${ }^{2}$ Krista V. Siagian
}

\author{
${ }^{1}$ Kandidat Skripsi Program Studi Pendidikan Dokter Gigi Fakultas Kedokteran \\ ${ }^{2}$ Program Studi Pendidikan Dokter Gigi Universitas Sam Ratulangi Manado \\ E-mail: lucyana_virgo91@yahoo.com
}

\begin{abstract}
Pregnancy is a very unique phase on every women marked with complex physiologic changes that can affect the healthiness of the oral cavity. The increased risk of mouth disease on pregnant women can be affected by the surge of estrogen and progesterone that marked by swelling and inflammation on the teeth. The General purpose of this research is to identify the clinical conception of the gingiva on pregnant women on Puskesmas Bahu in Malalayang residency. This research is tend to be observational descriptive with the cross-sectional approach. Population of this research is all the pregnant women that made a visit to Puskesmas Bahu in the period of January to February 2015 with 60 samples. The research on pregnant women can be divided with the scoring of gingiva clinical conception which is 0 for normal and 1 for abnormal on the color, size, contour, consistency and texture of the gingiva. The research result shows that the clinical picture of the gingiva on pregnant women are generally experience changes the texture of the gingiva (75\%), followed by the gingiva consistency (73\%), contour of the gingiva (58\%), color of the gingiva (48\%) and the size of the gingiva(43\%). On the age category, the highest value of the percentage present on age 36 to 45 years old especially the changes on the texture of the gingiva (86\%). On the category of age of the pregnancy, the highest value of the percentage present on the third trimester especially the changes of the the gingival consistency (86\%).
\end{abstract}

Keywords: the clinical picture of gingiva, pregnant women

\begin{abstract}
Abstrak: Kehamilan ialah masa yang sangat unik pada setiap wanita yang ditandai dengan perubahan fisiologis secara kompleks, sehingga dapat memengaruhi kesehatan rongga mulut. Peningkatan resiko terjadinya penyakit mulut pada wanita hamil dapat disebabkan oleh peningkatan hormon estrogen dan progesteron yang biasanya ditandai dengan pembengkakan dan peradangan pada gingiva. Tujuan dari penelitian ini ialah untuk mengetahui gambaran klinis gingiva pada ibu hamil di Puskesmas Bahu Kecamatan Malalayang. Penelitian ini bersifat deskriptif observasional dengan pendekatan cross sectional. Populasi dalam penelitian ini ialah seluruh ibu hamil yang dating berkunjung ke Puskesmas Bahu Kecamatan Malalayang pada bulan Januari - Februari tahun 2015 dengan jumlah sampel sebanyak 60 sampel. Penelitian pada ibu hamil dapat dibedakan dengan pembagian skor gambaran klinis gingiva yaitu normal sama dengan 0 dan tidak normal sama dengan 1 pada warna gingiva, besar gingiva, kontur gingiva, konsistensi gingiva dan tektur gingiva. Hasil dari penelitian ini menunjukkan bahwa gambaran klinis gingiva pada ibu hamil kebanyakkan mengalami perubahan pada tekstur gingiva (75\%), diikuti berurutturut konsistensi gingiva (73\%), kontur gingiva (58\%), warna gingiva (48\%) dan besar gingiva (43\%). Pada kategori umur presentase terbesar terdapat pada umur 36-45 tahun khususnya perubahan pada tekstur gingiva (86\%). Pada kategori usia kehamilan presentase terbesar terdapat pada trimester ke - III khususnya perubahan pada konsistensi gingiva (86\%).
\end{abstract}

Kata kunci: gambaran klinis gingiva, ibu hamil 
Kehamilan ialah masa yang sangat unik pada setiap wanita yang ditandai dengan perubahan fisiologis secara kompleks, sehingga dapat memengaruhi kesehatan rongga mulut. ${ }^{1}$ Peningkatan resiko terjadinya penyakit mulut pada wanita hamil dapat disebabkan oleh beberapa faktor seperti refleks muntah (gagging), nausea dan muntah yang dapat meningkatkan resiko terjadinya karies gigi, rasa takut menggosok gigi karena keadaan gingiva yang dapat meradang pada masa kehamilan, bahkan perubahan perilaku atau kebiasaan seperti mengabaikan kebersihan rongga mulut yang dapat meningkatkan frekuensi karies dan penyakit periodontal. ${ }^{2}$

Gingiva merupakan bagian dari jaringan periodontal yang paling luas. Gingiva sering kali dipakai sebagai indikator bila jaringan periodontal terkena penyakit. $^{3}$ Hal ini disebabkan karena kebanyakan penyakit periodontal dimulai dari gingiva.

Menurut hasil penelitian yang dilakukan oleh Hendro di Puskesmas Tuminting Kecamatan Tuminting, Kota Manado pada Tahun 2013 status gingiva pada ibu hamil berdasarkan pengukuran indeks gingiva terdapat paling banyak inflamasi ringan yaitu 60\%. Ibu hamil dengan usia kehamilan trimester III memiliki indeks gingiva lebih tinggi karena merupakan puncak terjadinya gingivitis pada kehamilan, sedangkan tingkat pendidikan dan tingkat penghasilan tidak bisa menjamin seseorang memiliki indeks gingiva yang lebih baik. ${ }^{4}$

Perawatan gigi pencegahan, diagnostik dan restoratif yang aman selama kehamilan sangat efektif dalam memelihara serta meningkatkan derajat kesehatan rongga mulut. Hal ini disebabkan karena kebanyakan penyakit periodontal dimulai dari gingiva, karena kesehatan mulut merupakan kunci dari kesehatan secara keseluruhan. ${ }^{1}$

Puskesmas Bahu merupakan salah satu puskesmas yang berada di Kecamatan Malalayang yang memberikan layanan kuratif, preventif, promotif, dan rehabilitatif. Pada survey awal yang dilakukan peneliti pada ibu hamil di Puskesmas Bahu didapati banyak keluhan mengenai gangguan didalam rongga mulut, keluhan yang dialami misalnya gigi berlubang dan penyakit periodontal seperti gingivitis dan periodontitis.

Sosialisasi mengenai pemeliharaan rongga mulut selama masa kehamilan masih jarang dilakukan di Puskesmas tersebut. Ibu hamil juga lebih banyak memeriksakan kehamilannya dibandingkan dengan memeriksakan kesehatan rongga mulut. Di Puskesmas Bahu pada umumnya Ibu hamil tidak secara rutin memeriksakan kehamilannya. Kenyataannya ibu hamil yang berkunjung ke Puskesmas Bahu sudah berada pada usia kandungan lebih dari 3 bulan. Berdasarkan latar belakang di atas maka peneliti merasa tertarik untuk melakukan penelitian tentang gambaran klinis gingiva pada ibu hamil di Puskesmas Bahu Kecamatan Malalayang.

\section{METODE PENELITIAN}

Rancangan penelitian ini ialah deskriptif observasional dengan pendekatan potong lintang. Tempat penelitian dilakukan di Puskesmas Bahu Kecamatan Malalayang pada bulan Januari - Februari 2015. Populasi penelitian ini ialah seluruh ibu hamil yang berkunjung di Puskesmas Bahu Kecamatan Malalayang. Sampel penelitian ialah total populasi yaitu seluruh ibu hamil yang berkunjung di Puskesmas Bahu Kecamatan Malalayang.

\section{HASIL PENELITIAN \\ Karakteristik Responden}

Karakteristik responden dalam penelitian ini ialah umur dan usia kehamilan. Kelompok umur 15-25 tahun berjumlah 28 responden (47\%), kelompok umur 26-35 tahun berjumlah 25 responden (42\%) dan kelompok umur 36-45 tahun berjumlah 7 responden (11\%) (Tabel 1). Kategori trimester I berjumlah 9 responden (15\%), trimester II berjumlah 29 responden (48\%) dan pada trimester III berjumlah 22 responden (37\%) (Tabel 1). 
Tabel 1. Distribusi karakteristik responden berdasarkan umur dan usia kehamilan.

\begin{tabular}{llll}
\hline Karakteristik Responden & & n & $\mathbf{( \% )}$ \\
\hline \multirow{3}{*}{ Umur } & $15-25$ & 28 & 47 \\
Total & $26-35$ & 25 & 42 \\
& $36-45$ & 7 & 11 \\
\multirow{2}{*}{ Usia kehamilan } & & 60 & 100 \\
& Trimester I & 9 & 15 \\
Total & Trimester II & 29 & 48 \\
& Trimester III & 22 & 37 \\
& & 60 & 100
\end{tabular}

\section{Gambaran klinis gingiva pada ibu hamil}

Pada penelitian ini gambaran klinis gingiva pada ibu hamil dibagi atas dua kategori yakni kategori normal dan kategori tidak normal. Tabel 2 menunjukkan bahwa gambaran klinis gingiva tidak normal dengan persentase terbesar berada pada tekstur gingiva dengan jumlah 45 responden (75\%) dan konsistensi gingiva dengan jumlah 44 responden (73\%).

\section{Gambaran klinis gingiva berdasarkan usia kehamilan responden}

Distribusi gambaran klinis gingiva pada ibu hamil berdasarkan usia kehamilan trimester I, trimester II dan trimester III dapat dilihat pada Tabel 3, 4 dan 5. Usia kehamilan trimester I berjumlah 9 responden dengan persentase terbesar terdapat pada warna gingiva dengan jumlah 7 responden $(78 \%)$.

Usia kehamilan trimester II berjumlah 29 responden dengan persentase terbesar terdapat pada gambaran klinis gingiva tidak normal yaitu berada pada tekstur gingiva dengan jumlah 22 responden (76\%) dan konsistensi gingiva dengan jumlah 20 responden (69\%).

Usia kehamilan trimester III berjumlah 22 responden pada gambaran gingiva tidak normal persentase terbesar yaitu pada konsistensi gingiva dengan jumlah 19 responden (86\%) dan tekstur gingiva dengan jumlah 18 responden (82\%).

Tabel 2. Gambaran klinis gingiva normal dan tidak normal pada ibu hamil

\begin{tabular}{llllllll}
\hline $\begin{array}{l}\text { Gambaran } \\
\text { Gingiva }\end{array}$ & Klinis & \multicolumn{9}{l}{ Keadaan (skor gingiva) } \\
& Normal & \multicolumn{3}{c}{ Tidak normal } & Total \\
& N & $\mathbf{0}$ & n & \% & N & \% \\
\hline Warna gingiva & 31 & 52 & 29 & 48 & 60 & 100 \\
Besar gingiva & 34 & 57 & 26 & 43 & 60 & 100 \\
Kontur gingiva & 25 & 42 & 35 & 58 & 60 & 100 \\
Konsistensi gingiva & 16 & 27 & 44 & 73 & 60 & 100 \\
Tekstur gingiva & 15 & 25 & 45 & 75 & 60 & 100 \\
\hline
\end{tabular}

Tabel 3. Gambaran klinis gingiva berdasarkan usia kehamilan trimester I

\begin{tabular}{|c|c|c|c|c|c|c|}
\hline \multirow{3}{*}{$\begin{array}{c}\text { Gambaran Klinis } \\
\text { Gingiva }\end{array}$} & \multicolumn{4}{|c|}{ Usia Kehamilan Trimester I } & \multicolumn{2}{|c|}{ Total } \\
\hline & \multicolumn{2}{|c|}{ Normal } & \multicolumn{2}{|c|}{ Tidak normal } & & \\
\hline & $\mathrm{N}$ & $\%$ & $\mathrm{n}$ & $\%$ & $\mathrm{~N}$ & $\%$ \\
\hline Warna gingiva & 2 & 22 & 7 & 78 & 9 & 100 \\
\hline Besar gingiva & 4 & 44 & 5 & 56 & 9 & 100 \\
\hline Kontur gingiva & 5 & 56 & 4 & 44 & 9 & 100 \\
\hline Konsistensi gingiva & 4 & 44 & 5 & 56 & 9 & 100 \\
\hline Tekstur gingiva & 4 & 44 & 5 & 56 & 9 & 100 \\
\hline
\end{tabular}


Angwirawan, Ticoalu, Siagian: Gambaran klinis gingiva...

Tabel 4. Gambaran klinis gingiva berdasarkan usia kehamilan trimester II

\begin{tabular}{lcccccc}
\hline \multicolumn{1}{c}{\begin{tabular}{c} 
Gambaran Klinis \\
\multicolumn{1}{c}{ Gingiva }
\end{tabular}} & \multicolumn{2}{c}{ Usia Kehamilan Trimester II } & \multicolumn{2}{c}{ Total } \\
& $\mathrm{n}$ & $\%$ & $\mathrm{n}$ & $\%$ & $\mathrm{~N}$ & $\%$ \\
\hline Warna gingiva & 13 & 45 & 16 & 55 & 29 & 100 \\
Besar gingiva & 20 & 69 & 9 & 31 & 29 & 100 \\
Kontur gingiva & 11 & 38 & 18 & 62 & 29 & 100 \\
Konsistensi gingiva & 9 & 31 & 20 & 69 & 29 & 100 \\
Tekstur gingiva & 7 & 24 & 22 & 76 & 29 & 100 \\
\hline
\end{tabular}

Tabel 5. Gambaran klinis gingiva berdasarkan usia kehamilan trimester III

\begin{tabular}{lcccccc}
\hline \multirow{2}{*}{\begin{tabular}{c} 
Gambaran Klinis \\
\multicolumn{1}{c}{ Gingiva }
\end{tabular}} & \multicolumn{2}{c}{ Usia Kehamilan Trimester III } & \multicolumn{2}{c}{ Total } \\
& $\mathrm{N}$ & $\%$ & $\mathrm{n}$ & $\%$ & $\mathrm{n}$ & $\%$ \\
\hline Warna gingiva & 16 & 73 & 6 & 27 & 22 & 100 \\
Besar gingiva & 10 & 45 & 12 & 55 & 22 & 100 \\
Kontur gingiva & 9 & 41 & 13 & 59 & 22 & 100 \\
Konsistensi gingiva & 3 & 14 & 19 & 86 & 22 & 100 \\
Tekstur gingiva & 4 & 18 & 18 & 82 & 22 & 100 \\
\hline
\end{tabular}

\section{BAHASAN}

Berdasarkan data hasil penelitian menunjukkan bahwa secara umum terjadi perubahan keadaan gingiva pada responden terlebih pada konsistensi gingiva dan tekstur gingiva dengan persentase terbesar berada pada tekstur gingiva sebesar $75 \%$ dimana permukaan gingiva menjadi licin serta terdapat pembengkakan dan mudah berdarah (tabel 2). Jika kesehatan rongga mulut pada ibu hamil tidak dilakukan pemeriksaan dan perawatan yang benar, maka nantiya dapat menyebabkan adanya jaringan yang tumbuh yang disebut tumor jinak atau dalam istilah kedokteran disebut epulis gravidarum. Hal ini karena terjadinya pelunakan dari jaringan daerah gusi akibat peningkatan hormon. ${ }^{5}$ Pembengkakan yang terjadi pada gusi mencapai puncaknya pada bulan ketujuh dan kedelapan. Hasil penelitian ini didukung oleh penelitian yang dilakukan oleh Taheri dkk (2013) yang mengatakan bahwa biasanya $80 \%$ responden mengalami pembengkakan gingiva serta perubahan tekstur gingiva yang mengakibatkan gingiva menjadi mengkilap dan bentuk gingiva menjadi bergelombang. ${ }^{6}$

Keadaan kesehatan rongga mulut pada ibu yang hamil di usia muda lebih berkaitan dengan faktor pengetahuan. Rata-rata ibu hamil yang dijumpai di Puskesmas Bahu minim pengetahuan mengenai pemeliharaan kesehatan rongga mulut hal ini dapat dilihat pada kunjungan ibu hamil di Puskesmas Bahu yang hanya berkunjung untuk memeriksakan kehamilannya namun tidak memeriksakan kesehatannya secara menyeluruh. Selama masa kehamilan seringkali ibu hamil lupa untuk menjaga kesehatan gigi dan mulutnya karena kesibukan pekerjaan atau kegiatan mengunjungi klinik bersalin serta menyiapkan pakaian atau kamar untuk calon bayinya sehinga selama kurun waktu tersebut ibu hamil mengabaikan perawatan rongga mulutnya baik dalam menjaga kebersihan mulut maupun memeriksakan ke dokter gigi. ${ }^{7}$

Berdasarkan hasil penelitian mengenai keadaan gingiva ibu hamil berdasarkan usia kehamilan memberikan gambaran bahwa 
pada usia kehamilan trimester ke III merupakan usia kehamilan yang sangat rentan akan penyakit periodontal dibandingkan dengan usia kehamilan pada trimester I dan II. Pada trimesterke III keadaan gingiva cenderung mengalami perubahan yang signifikan terutama pada konsistensi gingiva dimana biasanya pada keadaan gingiva normal permukaan gingiva tidak dapat digerakkan dan kenyal namun pada penelitian ini didapati permukaan gingiva terdapat pembentukkan saku dan mudah berdarah. Perubahan konsistensi gingiva ini dijumpai pada 19 responden sebanyak 86\% (tabel 5). Hal ini kemungkinan berkaitan dengan peningkatan hormon estrogen dan progesteron pada trimester ke III sehingga terjadi pelunakkan dari jaringan gusi akibat peningkatan hormon tersebut. ${ }^{8}$ Penelitian ini ditunjang oleh penelitian yang dilakukan Aritonang yang menyebutkan bahwa pada trimester II ke trimester ke III terjadi peningkatan hormon estrogen maupun progesteron serta memiliki perbedaan yang bermakna dimana pada trimester ke III indeks gingivitis cenderung lebih besar dibandingkan dengan trimester II. Meskipun setelah kelahiran akan hilang dengan sendirinya tetapi tetap akan merupakan sumber peradangan bila kebersihan gigi dan mulut tidak terpelihara. $^{9}$

Target penting dalam merencanakan perawatan gigi bagi wanita hamil adalah mencapai lingkungan rongga mulut yang sehat dan kebersihan rongga mulut yang optimal. Hal ini meliputi program kontrol plak yang dapat meminimalisir inflamasi pada jaringan gusi akibat lokal iritan yang biasanya menyertai perubahan hormon pada kehamilan. Instruksi agar menjaga kebersihan mulut meliputi teknik membersihkan rongga mulut harus diajarkan, diperkuat dan dimonitor. Konseling diet, dengan pembatasan konsumsi karbohidrat tertentu perlu dilakukan. Scaling (pembersihan karang gigi) dan atau kuretase akar dapat dilakukan kapanpun diperlukan. Plak kontrol sebagai pencegahan harus dilaksanakan sejak trimester pertama. Hal ini perlu dilakukan sesering mungkin untuk mengontrol penyebab lokal dan mengurangi inflamasi pada gusi. $^{10}$

\section{SIMPULAN}

Gambaran klinis gingiva pada ibu hamil berdasarkan usia kehamilan menunjukkan bahwa usia kehamilan pada trimester ke III sebagai usia kehamilan yang paling banyak mengalami perubahan pada gingiva khususnya pada konsistensi gingiva yaitu terdapat pembentukan saku dan mudah berdarah.

\section{SARAN}

1. Bagi Institusi Kesehatan agar secara rutin melaksanakan progam atau penyuluhan dalam rangka memromosikan kesehatan gigi dan mulut ibu hamil.

2. Bagi masyarakat, khususnya ibu hamil untuk dapat merawat dan memelihara kesehatan gigi dan mulut selama masa kehamilan, baik dalam menjaga kebersihan mulut maupun pengontrolan ke dokter gigi

\section{DAFTAR PUSTAKA}

1. A National Consensus Statement Summary of an Expert Workgroup. Oral Health Care During Pregnancy. Washington DC: Nasional Maternal and Child Oral Health Resource Center Goergetown University. 2012: 1-2

2. Hidayati, Kuswandani, Gustria R. Pengaruh Kebersihan Gigi dan Mulut Dengan Status Gingivitis Pada Ibu Hamil Di Wilayah Kerja Puskesmas Andalas Kecamatan Padang Timur Kota Padang Tahun 2012. Majalah Kedokteran Andalas. Juli - Desember 2012. No. 2, Vol. 36

3. Pirie M, Cooke I, Linden G. Dental Manifestation of Pregnancy. London: The Obstetrician and Gynaecologist Royal Collage 2007: 9,21-26

4. Yoto H. Gambaran Gingivitis Pada Ibu Hamil Di Puskesmas Tuminting. Jurnal E-Gigi Juli - Desember 2013. Vol. 1, No. 2:1-9

5. Rie. Kesehatan Gigi Dan Mulut Pada Ibu Hamil. [serial online] 2012 [cited 2015 Maret 16]. Available from: 
http://www.rumahsehatterpadu.or.id/20 12/11 /14/kesehatan-gigi-dan-mulutpada-ibu-hamil/

6. Taheri JB, Azimi S, Mathew A, et al. Comparison of Periodontal Status between Pregnant and Nonpregnant Women. International Journal of Experimental Dental Science. JuliDecember 2013: (2):82-85

7. Prawirohardjo S. Ilmu Kebidanan Ed Ke4. Jakarta: PT Bina Pustakan Sarwono Prawirohardjo; 2009: 213

8. Warongan G. Gambaran Status Gingiva Pada Ibu Hamil Di Puskesmas Bahu
Manado. Jurnal e-GiGi (eG). Januari Juni 2015. Vol. 3, No. 1:141-146

9. Aritonang I, Manurung NK, Nurasniwati S. Hubungan Umur Kehamilan Ibu Dengan Keadaan Gingivitis Di Desa Patumbak I dan II Kecamatan Patumbak Kabupaten Deli Serdang Tahun 2012. Jurnal Dosen Luar. Maret - Juli 2012: 1-6

10.Little J.W. et al. Dental management of the medically compromised patient. 2002. $6^{\text {th }}$ edition. Mosby Inc. St Louis. Missourri. p. 45-9. 